\title{
Incidence and prognosis of obstruction of the left ventricular outflow tract in Liverpool (1960 - 91): a study of 313 patients
}

\author{
D Kitchiner, M Jackson, N Malaiya, K Walsh, I Peart, R Arnold
}

\begin{abstract}
Objective-To determine the incidence of the various types of obstruction of the left ventricular outflow tract in patients born in the five health districts of Liverpool and to compare their prognosis into early adult life.

Design-Notes of all patients with obstruction of the left ventricular outflow tract born in the study area between 1960 and 1991 were reviewed. Patients with hypoplastic left ventricle, mitral valve atresia, and those with discordant atrioventricular or ventriculoarterial connections were excluded. Survivors were traced and assessed clinically; eight were lost to follow up.
\end{abstract}

Results-Obstruction of the left ventricular outflow tract occurred in 313 patients (67\% male), giving an incidence of $6 \cdot 1 / 10000$ live births. The median (range) age at presentation was 13.9 months (0-20 yr). Aortic valve stenosis occurred in $71.2 \%$ : subvalve in $13.7 \%$, supravalve in $7 \cdot 7 \%$, and multilevel in $7 \cdot 4 \%$. The median (range) duration of follow up was 10.0 (1-29) yr. Aortic regurgitation at presentation occurred more often $(p<0.001)$ in patients with subvalve stenosis than in those with other types of obstruction, but there was an increased incidence $(p<0.001)$ at follow up in patients with valve stenosis. Ninety eight patients $(31 \cdot 3 \%)$ underwent operation. The reoperation rate was $27 \%$ for valve stenosis and $9 \%$ for subvalve obstruction. No patients with supravalve stenosis underwent reoperation. The median duration from first operation to aortic valve replacement (17 patients) was 12.3 years. Hazard analysis confirmed that the risk of death was higher in patients presenting at a younger age, with more severe stenosis, and those with subaortic, multilevel obstruction or a syndrome. Hazard analysis also showed that the risk of a clinical event (surgery, balloon dilatation, or endocarditis) was greater in patients who presented at a younger age, with more severe stenosis or aortic regurgitation, and in those with subvalve or multilevel obstruction.

Conclusions-Aortic valve stenosis was the most common type of obstruction. Hazard analysis indicates that the age and severity of obstruction at presentation have a significant effect on survival and freedom from a clinical event. The risk of premature death in patients presenting with moderately severe valve stenosis is reasonably small, but increases considerably in those with subvalve, supravalve, and multilevel obstruction. Patients who present with mild valve stenosis have a good prognosis. The risk of sudden death is less than previous predictions. Patients with subvalve and multilevel obstruction, even when mild at presentation, are more likely to undergo intervention or develop endocarditis than those with valve or supravalve stenosis. Follow up into adult life is essential.

\section{(Br Heart F 1994;71:588-595)}

Obstruction of the left ventricular outflow tract encompasses a number of conditions and most reports have been confined to a single group. ${ }^{1-3}$ The aims of this study were to determine the incidence of the various types of obstruction of the left ventricular outflow tract in the five health districts of Liverpool that make up the Merseyside area, and to compare prognosis into early adult life.

Patients and methods

The records of the Liverpool Congenital Malformations Registry and the cardiac unit of the Royal Liverpool Children's Hospital identified 313 patients $(210$ males, 103 females) with obstruction of the left ventricular outflow tract born in the study area between 1 January 1960 and 31 December 1990. Methods of identification of patients were the same as those used in a previous study. ${ }^{4}$ Patients with hypoplastic left ventricle, mitral valve atresia, and those with discordant atrioventricular or ventriculoarterial connections were excluded. The number of children with congenital heart disease and the live birth rate were available for the Liverpool and Bootle districts only, from 1960 to 1978 . 
From 1979 to 1990 data were available for all five health districts.

The type of obstruction was determined by review of clinical, echocardiographic, angiographic, operative, and postmortem information. The severity of obstruction at presentation was determined from the clinical findings and electrocardiogram. Results of Doppler echocardiography and cardiac catheterisation were also used, if performed within a year of presentation. The presence of aortic regurgitation and other cardiac lesions was noted. The criteria used to assess the severity of stenosis have been described in a previous study. ${ }^{4}$ Isolated aortic valve stenosis occurred in 223 patients (146 male, 77 female), subvalve stenosis in 43 (31 male, 12 female), supravalve in 24 (16 male, eight female), and multilevel obstruction in 23 (17 male, six female). In most cases this consisted of valve and subvalve obstruction, but five patients had valve, subvalve, and supravalve obstruction.

All patients' records were reviewed for details of important clinical events such as cardiac catheterisation, balloon dilatation, endocarditis, cardiac surgery, and death. An attempt was made to contact all survivors and clinical assessment consisted of physical examination, 12 lead electrocardiogram, and cross sectional and continuous wave Doppler ( 1.9 or $2.0 \mathrm{Mhz}$ ) echocardiography with an Irex Meridian or Hewlett-Packard Sonos 500 ultrasound system. In 25 patients, data were obtained from the cardiologist maintaining follow up into adult life. Eight patients were lost to follow up. The aim was to determine the incidence of intervention and the current clinical state of all patients.

\section{STATISTICAL ANALYSIS}

Descriptive statistics are presented as median (range) for continuously distributed variables,

Table 1 Median (range) age, severity of stenosis, and incidence of aortic regurgitation

\begin{tabular}{lclll}
\hline & \multicolumn{4}{l}{ Level of obstruction } \\
\cline { 2 - 5 } & $\begin{array}{l}\text { Valve } \\
(n=223(\%))\end{array}$ & $\begin{array}{l}\text { Subvalve } \\
(n=43(\%))\end{array}$ & $\begin{array}{l}\text { Supravalve } \\
(n=24(\%))\end{array}$ & $\begin{array}{l}\text { Multilevel } \\
(n=23(\%))\end{array}$ \\
\hline Age (months) & $19 \cdot 4(0-181)$ & $6 \cdot 2^{*}(0-171)$ & $15 \cdot 0(0-56)$ & $1 \cdot 7(0-52)$ \\
Stenosis: & $179(80 \cdot 3)$ & $32(74 \cdot 4)$ & $14(58 \cdot 3)$ & $9(39 \cdot 1)$ \\
$\quad$ Insignificant to mild & $23(10 \cdot 3)$ & $10(23 \cdot 3)$ & $8(33 \cdot 3)$ & $12(52 \cdot 2)$ \\
Moderate & $21(9 \cdot 4)$ & $1(2 \cdot 3)$ & $2(8 \cdot 4)$ & $2(8 \cdot 7)$ \\
Severe to critical & $6(3)$ & $21(49)$ & 0 & $5(22)$ \\
Aortic regurgitation & &
\end{tabular}

ॠ Median age at presentation in those without other cardiac lesions was 38 months.

Table 2 Distribution of 194 other cardiac lesions in 114 patients (54 (47.4\%) patients had more than one lesion)

\begin{tabular}{llllll}
\hline \multicolumn{5}{l}{ Level of obstruction } \\
\cline { 2 - 5 } & $\begin{array}{l}\text { Valve } \\
(n=64(29 \%))\end{array}$ & $\begin{array}{l}\text { Subvalve } \\
(n=23(54 \%))\end{array}$ & $\begin{array}{l}\text { Supravalve } \\
(n=11(46 \%))\end{array}$ & $\begin{array}{c}\text { Multilevel } \\
(n=16(70 \%))\end{array}$ \\
\hline VSD/ASD/PDA & 48 & 30 & 3 & 18 \\
Coarctation & 44 & 13 & 1 & 9 \\
Mitral lesion & 6 & 3 & -9 & 2 \\
RVOTO & 1 & 4 & - & 1 \\
TS & & 1 & 13 & 31 \\
Total & 99 & 51 & 1 & \\
\hline
\end{tabular}

ASD, Atrial septal defect; PDA, patent ductus arteriosus; RVOTO, right ventricular outflow tract obstruction; TS, tricuspid stenosis; VSD, ventricular septal defect. or proportions with $70 \%$ confidence intervals (70\% CIs) for categorical variables. The possibility that differences were not due to chance was explored with the Wilcoxon rank sum test, the $\chi^{2}$ statistic with trend, ${ }^{5}$ or Yates corrected Fishers exact test as appropriate. Survival and freedom from first clinical event (surgery, balloon dilatation, or endocarditis) were analysed actuarially with the product limit method of Kaplan and Meier. ${ }^{6}$ Distributions for death and first clinical event were modelled parametrically and the hazard function determined. ${ }^{7}$ Risk factors for these events were elucidated by multivariate hazard analysis. ${ }^{7}$ Variables were considered significant where $p \leqslant 0.05$. The variables considered in all multivariate analyses were age and severity of aortic stenosis at presentation, type of obstruction of the left ventricular outflow tract, sex, presence of a syndrome, presence of aortic regurgitation at presentation, and presence of other cardiac lesions. Indicator variables were derived for severity of aortic stenosis (mild, moderate, severe to critical) and cardiac lesion groups (septal defects and patent arterial duct, aortic arch anomalies, mitral valve disease, or pulmonary stenosis).

\section{Results}

Obstruction of the left ventricular outflow tract occurred in 112 of the 239669 live births in the Liverpool and Bootle areas during the years 1960 to 1978 , giving an incidence of 4.6 in 10000 live births. Between 1979 and 1990 obstruction of the left ventricular outflow tract occurred in 137 of the 224558 live births in the five health districts of the Merseyside area, giving an incidence of 6.1 in 10000 live births. This represents $7 \cdot 2 \%$ of children born with congenital heart disease in the Merseyside area during the study period. The 62 patients born within the Merseyside area but outside the Liverpool and Bootle area between 1960 and 1978, and the two patients born in 1990 were not included in the calculated incidence as live birth rates for these areas and years were not available.

Table 1 shows the median age and severity of obstruction at presentation. There was a significant difference in the incidence of mild stenosis with different types of obstruction $(p<0.001)$. An analysis trend $(p<0.001)$ indicated that progressively fewer patients presented with mild stenosis in the valve, subvalve, supravalve, and multilevel groups. Aortic regurgitation at presentation (table 1) was more common in patients with subvalve stenosis than in the other groups $(p<0.001)$. One hundred and ninety four other cardiac lesions occurred in 114 patients (table 2). Other cardiac lesions were more common in patients with subvalve $(p=0.003)$ or multilevel obstruction $(\mathrm{p}<0.001)$ than in those with valve stenosis.

\section{SYNDROMES}

Thirty seven patients had a syndrome or familial supravalve aortic stenosis. Five 
Table 3 Patients (n(\%)) who underwent operation related to the severity of stenosis at presentation

\begin{tabular}{|c|c|c|c|c|}
\hline \multirow{2}{*}{$\begin{array}{l}\text { Severity at } \\
\text { presentation }\end{array}$} & \multicolumn{4}{|c|}{ Level of obstruction } \\
\hline & Valve & Subvalve & Supravalve & Multilevel \\
\hline \multirow{2}{*}{$\begin{array}{l}\text { Mild stenosis } \\
\text { Moderate stenosis } \\
\text { Severe to critical } \\
\text { stenosis }\end{array}$} & $\begin{array}{l}24(16) \\
15(65)\end{array}$ & $\begin{array}{r}14(44) \\
8(80)\end{array}$ & $\begin{array}{l}5(36) \\
5(63)\end{array}$ & $\begin{array}{l}6(67) \\
8(65)\end{array}$ \\
\hline & $9^{\star}(43)$ & $0^{\star}$ & $2(100)$ & $2(100)$ \\
\hline
\end{tabular}

$\star 12$ patients with valve stenosis and one patient with subvalve stenosis died before operation could be performed.

patients with Turner's syndrome had valve stenosis. All 13 patients with Williams' syndrome had supravalve stenosis. A further 11 patients had familial supravalve aortic stenosis. Eight patients with subvalve or multilevel obstruction had syndromes. Two had Noonan's syndrome, two had Shone's syndrome, and one had rubella syndrome. One patient each had trisomy 13, trisomy 15 , and a $22 \mathrm{q}$ chromosome deletion, confirmed on chromosomal analysis.

\section{FOLLOW UP}

The median (range) duration of follow up in survivors was $10.0(1-29.2)$ years, which represented 3200 patient-years of follow up. Seven patients with mild obstruction at presentation who had showed no increase in severity and had not required intervention for 1-15 (median 3.7) years, were lost to follow up. One patient with valve and subvalve obstruction who had only mild residual stenosis after surgery was lost to further follow up.

\section{SURGERY}

Ninety eight patients (31.3\%) underwent 125 operations for obstruction of the left ventricular outflow tract. Forty eight of the patients with valve stenosis $(21 \cdot 5 \%)$ underwent operation, $22(51 \cdot 2 \%)$ of those with subvalve stenosis, $12(50.0 \%)$ of those with supravalve stenosis, and $16(69.6 \%)$ of those with with multilevel obstruction (table 3). Fewer patients with valve stenosis underwent operation than those with other types of obstruction $(p<0.001)$. This reflected the lower incidence of patients presenting with mild valve stenosis who progressed to require operation, compared with patients presenting with mild stenosis and other types of obstruction $(p<0.001)$. There was no significant difference in the number of patients with or without other cardiac lesions who underwent operation. The indication for the first opera-

Table 4 Median (range) age at first operation, reoperation rate, and median (range) duration between operations

\begin{tabular}{|c|c|c|c|c|}
\hline & \multicolumn{4}{|c|}{ Level of obstruction } \\
\hline & $\begin{array}{l}\text { Valve } \\
(n=48)\end{array}$ & $\begin{array}{l}\text { Subvalve } \\
(n=22)\end{array}$ & $\begin{array}{l}\text { Supravalve } \\
(n=12)\end{array}$ & $\begin{array}{l}\text { Multilevel } \\
(n=16)\end{array}$ \\
\hline $\begin{array}{l}\text { Age at first operation (yr) } \\
\text { Reoperation rate }(\mathrm{n}(\%))\end{array}$ & $\begin{array}{l}8 \cdot 8(0-22 \cdot 4) \\
13(27)\end{array}$ & $\begin{array}{l}10 \cdot 3(2-18 \cdot 2) \\
2(9)\end{array}$ & $6.3(0-22 \cdot 9)$ & $\begin{array}{l}6 \cdot 2 *(0-10 \cdot 5) \\
6(37 \cdot 5)\end{array}$ \\
\hline $\begin{array}{l}\text { Duration between } \\
\text { operations (yr) }\end{array}$ & $6 \cdot 3(3-18)$ & $7 \cdot 7(4 \cdot 5-10 \cdot 9)$ & - & $4 \cdot 6(1 \cdot 4-10 \cdot 1)$ \\
\hline
\end{tabular}

* In five patients with valve, subvalve, and supravalve stenosis, the median age at first operation was $1 \cdot 2$ years. tion in 90 patients was aortic stenosis with a peak systolic left ventricular outflow gradient at cardiac catheterisation of $>60 \mathrm{~mm} \mathrm{Hg}$ or the development of symptoms. In three patients the combination of aortic stenosis and regurgitation was the indication for operation. In five patients closure of a ventricular septal defect was the primary indication, but resection of a subaortic stenosis was also performed.

Table 4 shows the age at first operation and the duration between first and second operations. The reoperation rate for the group was $21 \cdot 4 \%$. Three patients with valve stenosis and three with multilevel obstruction required a third operation. The operative mortality related to the first operation was $14.3 \%$ ( $70 \%$ CI $10 \cdot 6 \%-18.9 \%)$ and at reoperation was $22 \cdot 2 \%$ ( $70 \%$ CI $13 \cdot 6 \%-33 \cdot 5 \%)$. Four initial operations were aortic valve replacement $(4 \%)$, seven second operations $(47 \%)$, and all six patients $(100 \%)$ who underwent a third operation had a valve replacement. The median (range) duration from first operation to aortic valve replacement was $12.3(2 \cdot 5-20 \cdot 6)$ years in those who did not have a valve replacement at initial operation.

\section{BALLOON DILATATION}

Balloon dilatation of the left ventricular outflow tract was undertaken 16 times in 14 patients. Eight patients with valve stenosis had nine balloon dilatations of the valve, and three patients with multilevel obstruction had four dilatations. Three patients with subvalve stenosis had balloon dilatation of the left ventricular outflow tract. Ten cases were successful. There were no significant difference in the success rates related to the various types of obstruction.

\section{INFECTIVE ENDOCARDITIS}

Infective endocarditis occurred in two patients $(0.9 \%)$ with valve stenosis, in two $(4.7 \%)$ with subvalve stenosis, and in one $(4 \cdot 3 \%)$ with multilevel obstruction, giving a rate of 1.6 in 1000 patient-years of follow up. Three patients died after having endocarditis.

\section{AORTIC REGURGITATION}

Aortic regurgitation was found in 78 of the 253 survivors $(30 \cdot 8 \%)$ who were followed up. Fifty two patients had valve stenosis, 20 had subvalve stenosis, and six had multilevel obstruction. Aortic regurgitation was mild in 65 patients and moderate in 13. There was no increase in the incidence at follow up in patients with subvalve or multilevel obstruction, but there was a significant increase $(p<$ 0.0001 ) in those with valve stenosis.

\section{SURVIVAL}

There were 52 deaths in the study group. Table 5 shows the operative mortality within one month of initial surgery and reoperation related to the type of obstruction. Three late postoperative deaths occurred; one patient with severe kyphoscoliosis developed restenosis, an infant developed cardiomyopathy after 
Table 5 Operative mortality in the 20 patients who died within a month of operation

\begin{tabular}{|c|c|c|c|c|}
\hline & \multicolumn{4}{|c|}{ Level of obstruction } \\
\hline & $\begin{array}{l}\text { Valve } \\
(n=64)\end{array}$ & $\begin{array}{l}\text { Subvalve } \\
(n=24)\end{array}$ & $\begin{array}{l}\text { Supravalve } \\
(n=12)\end{array}$ & $\begin{array}{l}\text { Multilevel } \\
(n=25)\end{array}$ \\
\hline $\begin{array}{l}\text { First operation } \\
\text { Reoperation } \\
\text { Operative mortality }(\mathrm{n}(\%))\end{array}$ & $\begin{array}{l}6^{*} \\
3 \\
9(14)\end{array}$ & $\frac{1}{1(4)}$ & $\frac{3}{3(25)}$ & $\begin{array}{l}4 \\
3 \\
7(28)\end{array}$ \\
\hline
\end{tabular}

^ Five patients had critical stenosis; one patient had aortic valve replacement.

surgery for critical aortic stenosis, and a third patient developed aortic regurgitation and cardiomyopathy after aortic valve replacement.

Twenty nine patients died without operation. There was a single unexpected death in a patient with subvalve stenosis and rubella syndrome. Two patients with familial supravalve aortic stenosis presented at five days and 17 months respectively and died before operation could be performed. All 10 patients with valve stenosis who died had critical stenosis and died before operation could be performed. Thirteen of the 37 patients with a syndrome $(35 \%)$ died; two patients had Noonan's syndrome, one had Williams' syndrome, one had Shone's syndrome, one

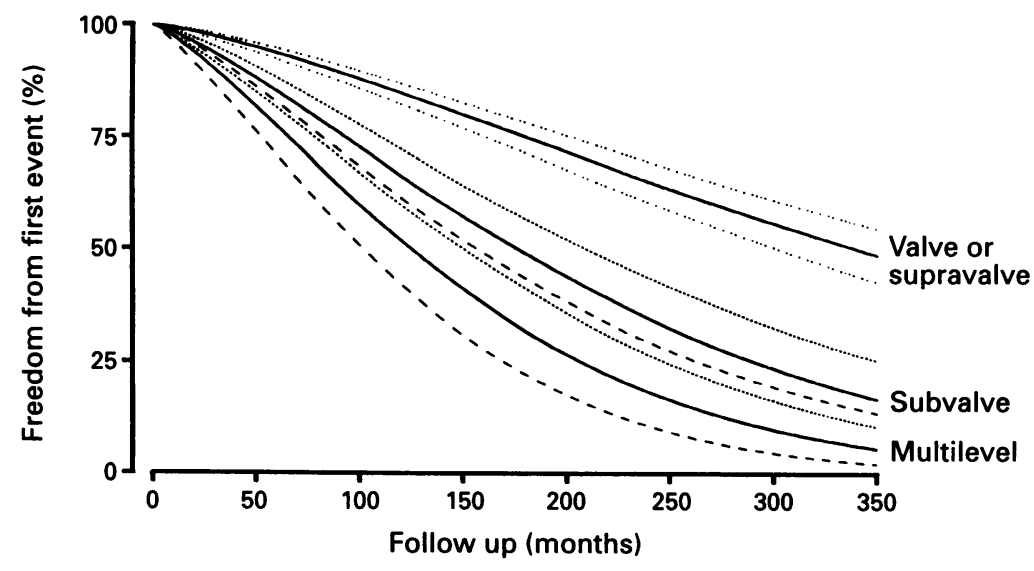

Figure 1 Predicted risk of death (and 70\% CIs) for a patient presenting at 13.9 months of age with moderate obstruction of the left ventricular outflow tract plotted against level of obstruction from a solution to equations developed by means of hazard analysis (appendix 1).

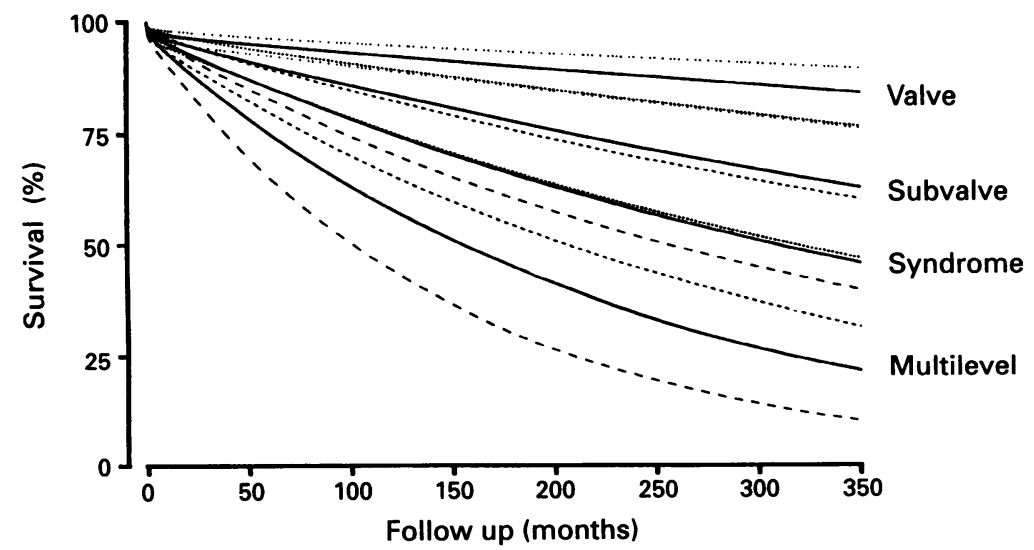

Figure 2 Predicted freedom from first clinical event (operation, balloon dilatation or endocarditis, and $70 \% \mathrm{CIs}$ ) for a patient presenting at 13.9 months of age with mild obstruction of left ventricular outflow tract without aortic regurgitation plotted against level of obstruction from equations developed by means of hazard analysis (appendix I). had rubella syndrome, three had chromosomal abnormalities, and five had familial supravalve aortic stenosis.

Hazard analysis showed two phases of hazard, an early rapidly declining phase and a constant phase (appendix 1). In the early phase, significant risk factors were found to be increasing severity of obstruction of the left ventricular outflow tract at presentation $(p<0.001)$, and younger age at presentation $(p<0.001)$. Significant risk factors in the constant phase were more severe obstruction of the left ventricular outflow tract at presentation $(p=0.004)$, the presence of multilevel obstruction $(p<0.001)$, the presence of subvalve obstruction $(p=0.09)$, and the presence of a syndrome or familial supravalve aortic stenosis $(p=0.003)$.

Hazard analysis predicts the risk of an event depending on one variable, when all other variables that have been shown to influence that event are held constant by means of mathematical modelling. The effect of any one variable can then be assessed. Figure 1 shows the predicted risk of premature death for a patient presenting at 13.9 months (the median age for the study group) with moderate stenosis, for the various types of obstruction of the left ventricular outflow tract. By holding the age and severity at presentation constant, the effect on survival of the only remaining risk factor (the type of obstruction) could be assessed. Supravalve stenosis did not emerge as an independent risk factor. As all but one patient with supravalve stenosis had a syndrome or familial supravalve aortic stenosis, the curve showing the prognosis of a patient with a syndrome is a good indicator of the prognosis of a patient with supravalve stenosis. Figure 1 shows that, where the only free variable is the type of obstruction, the risk of premature death is progressively greater in patients with valve, subvalve, supravalve, and multilevel obstruction.

\section{FREEDOM FROM FIRST CLINICAL EVENT}

Hazard analysis was also used to assess the risk of an important clinical event (surgery, balloon dilatation, or endocarditis). As with the risk of premature death, two phases of hazard were resolved. The small early phase was rapidly followed by a constant phase that dominated the event free distribution (appendix 1). The distribution was therefore best modelled with a single late phase model (EH Blackstone, personal communication, appendix 2). Significant risk factors were found to be the severity of obstruction of left ventricular outflow tract at presentation $(p<0.001)$, the presence of severe to critical aortic stenosis at presentation ( $p<0.001)$, age at presentation $(p<0.001)$, presence of aortic valve regurgitation at presentation $(p=0.05)$, presence of subvalve stenosis $(p<0.001)$, and the presence of multilevel obstruction $(p<0.001$, appendix 1).

Figure 2 shows the chance of being free from a clinical event for a patient presenting with mild left ventricular outflow obstruction at 13.9 months without a syndrome or aortic 
Table 6 Current state in all patients (each patient appears only once)

\begin{tabular}{|c|c|c|c|c|}
\hline & \multicolumn{4}{|c|}{ Level of obstruction } \\
\hline & $\begin{array}{l}\text { Valve } \\
(n=223(\%))\end{array}$ & $\begin{array}{l}\text { Subvalve } \\
(n=43(\%))\end{array}$ & $\begin{array}{l}\text { Supravalve } \\
(n=24(\%))\end{array}$ & $\begin{array}{l}\text { Multilevel } \\
(n=23(\%))\end{array}$ \\
\hline Mild & $115(51 \cdot 6)$ & $11(25.6)$ & $7(29 \cdot 2)$ & $3(13 \cdot 0)$ \\
\hline $\begin{array}{l}\text { Moderate } \\
\text { Severe }\end{array}$ & $\begin{array}{c}28(12.5) \\
1(0.5)\end{array}$ & $3(7 \cdot 0)$ & $3(12 \cdot 5)$ & - \\
\hline Surgery & & & & \\
\hline $\begin{array}{c}+ \text { survived } \\
\text { Balloon dilatation }\end{array}$ & $37(16 \cdot 6)$ & $18(41 \cdot 9)$ & $9(37 \cdot 5)$ & $7(30 \cdot 4)$ \\
\hline $\begin{array}{l}\text { + survived } \\
\text { Endocarditis }\end{array}$ & $\begin{array}{l}6(2 \cdot 7) \\
1(0 \cdot 5)\end{array}$ & $\begin{array}{l}2(4 \cdot 6) \\
2(4 \cdot 6)\end{array}$ & - & - \\
\hline Died & $28(12 \cdot 5)$ & $7(16 \cdot 3)$ & $5(20 \cdot 8)$ & $12(52 \cdot 2)$ \\
\hline Lost & $7(3 \cdot 1)$ & - & - & $1(4 \cdot 4)$ \\
\hline
\end{tabular}

regurgitation. The only remaining risk factor is the type of obstruction of the left ventricular outflow tract. The chance of an important clinical event is higher in a patient with subvalve compared with valve or supravalve stenosis, but is highest in a patient with multilevel obstruction. After 20 years of follow up, the chance of being free of a clinical event is $65 \%(70 \%$ CI $60 \cdot 4 \%$ to $69 \cdot 3 \%)$ for such a patient with valve or supravalve stenosis, but only $34.4 \%(70 \%$ CI $26.5 \%$ to $43.4 \%)$ for a similar patient with subvalve stenosis and $18 \cdot 1 \%(70 \%$ CI $9 \cdot 0 \%$ to $27 \cdot 0 \%)$ for one with multilevel obstruction.

\section{CURRENT STATE}

Table 6 shows the current state in all patients. A significantly high proportion of patients with aortic valve stenosis still had mild obstruction without intervention, compared with patients with subaortic stenosis $(p=0.003)$.

\section{Discussion}

Early studies did not differentiate between patients with various types of obstruction of the left ventricular outflow tract, ${ }^{8-10}$ but it became clear that this comprised a number of different conditions. Edwards provided a classification but did not consider prognosis. ${ }^{11}$ Subsequently each type of obstruction was studied separately, with few reports comparing prognosis, ${ }^{12-14}$ apart from the results of operation. ${ }^{15-17}$ A number of authors stressed that multilevel obstruction was difficult to treat surgically. ${ }^{18-20}$

The incidence of obstruction to the left ventricular outflow tract in this study was higher than that previously reported, ${ }^{14} 2122$ but may still be lower than the true incidence. Patients moving from the area before diagnosis will not have been included, and some may have died suddenly before diagnosis. Infants have been included because of referral to the Congenital Malformations Registry, ${ }^{23} 24$ but sudden death in an older child may have been missed. This number is likely to be small as most patients present with mild stenosis, ${ }^{1425}$ and sudden death is rare. ${ }^{12627}$ The incidence for the period from 1979 to 1990 was higher than the previous years, probably due to more accurate diagnosis. Screening of a large population of children with serial echocardiography is the only way in which the true incidence can be determined. We studied patients born in a defined area to determine the relative incidence of the various types of obstruction of the left ventricular outflow tract. Previous hospital based studies indicated a similar distribution, with valve stenosis forming the largest group. ${ }^{151628}$ Multilevel obstruction formed a small but important group from the point of view of prognosis. ${ }^{181929}$

Aortic valve stenosis is often mild at presentation, ${ }^{1430}$ but the predominance of mild stenosis at presentation in patients with subvalve or supravalve stenosis had not previously been documented. Some patients (particularly those with subvalve stenosis) presented with other cardiac lesions and mild stenosis was subsequently detected. The association with Williams' syndrome $e^{31-33}$ or familial supravalve aortic stenosis ${ }^{3435}$ may have assisted in the early detection of supravalve stenosis. With the use of cross sectional and Doppler echocardiography mild stenosis can be diagnosed early. ${ }^{33}$. $^{36}$ The median age at presentation was similar in patients with valve and supravalve stenosis and in those with subaortic stenosis without other lesions. Patients with multilevel obstruction presented at a younger age with more severe stenosis than those with a single type of obstruction and the poor prognosis in this group was confirmed on follow up.

The incidence of aortic regurgitation at presentation was highest in patients with subvalve stenosis. ${ }^{810}$ This did not increase at follow up ${ }^{28.37}$ in contrast with patients with valve stenosis, ${ }^{2838}$ indicating that progression was significantly greater in patients with valve compared with subvalve stenosis. Other cardiac lesions were significantly more common in patients with subvalve and multilevel obstruction than in those with valve or supravalve stenosis, ${ }^{39}{ }^{40}$ and their distribution was similar to other published series. ${ }^{81416}$ The association of Williams' syndrome with supravalve aortic stenosis has been noted, ${ }^{33141}$ but the incidence was higher than in other published series. ${ }^{42}$ The incidence of familial supravalve stenosis ${ }^{34}{ }^{35}$ was also high because of the presence of two affected families in the Merseyside area. The true incidence of the familial type in the population is unknown. The two patients with Noonan's syndrome had multivalve abnormalities as well as subaortic stenosis and they form part of a separate report. ${ }^{43}$ Trisomy 15 is very rare but cardiac anomalies are known to occur. ${ }^{44}$

SURGERY

The comparative incidence of surgery in a group of patients with the various types of obstruction has not recently been documented. ${ }^{14}$ In studies of individual types of obstruction, the proportion of patients requiring operation in the first three decades of life was lowest in those with valve stenosis as found in this study. ${ }^{145}$ Fewer patients with subvalve stenosis underwent operation $(51 \%)$ than other series, ${ }^{4647}$ because patients with mild stenosis detected by echocardiography 
were included. Flaker et al found that $64 \%$ of patients with supravalve aortic stenosis underwent operation, which is similar to our study. ${ }^{42}$

Patients with multilevel obstruction had the highest operation and reoperation rates, confirming their poor prognosis. ${ }^{17} 1948$ In those with valve, subvalve, and supravalve obstruction, the median age at first operation was considerably lower than the rest of the group. Significantly fewer patients who presented with mild valve stenosis eventually required operation than similar patients with other types of obstruction. This confirmed the slower rate of progression in patients with mild valve stenosis. This was also shown by Keane et al in the second natural history study of congenital heart defects. ${ }^{49}$

The reoperation rate in patients with valve stenosis $(27 \%)$ was similar to other studies. ${ }^{49-57}$ The reoperation rate in patients with subvalve stenosis ( $9 \%$ ) was similar to the reported rate of $7 \%$ to $18 \%,{ }^{28} 4752$ and was less than that for patients with valve stenosis over a similar period of follow up. Stewart et al showed that the need for reoperation increased with time in all types of subaortic stenosis. ${ }^{37}$ There are few reports of long-term follow up in patients after repair of supravalve aortic stenosis, ${ }^{1742}$ but, as in this study, no patient required reoperation.

\section{BALLOON DILATATION}

The number of patients undergoing balloon dilatation was small and although its value in the treatment of aortic valve stenosis has been documented, ${ }^{53} 54$ its place in the treatment of subvalve and multilevel obstruction is yet to be established. The results in the treatment of subvalve stenosis are promising for some types of subaortic stenosis, ${ }^{55}$ but it may be important to define the anatomical types of subaortic stenosis more clearly before conclusions are drawn.

\section{ENDOCARDITIS}

Endocarditis is now an uncommon complication, ${ }^{156}$ but its association with subaortic stenosis has previously been emphasised, ${ }^{28} 46$ particularly in older patients. ${ }^{5257}$ The incidence in this study was low, but it was associated with a high mortality.

\section{SURVIVAL}

Sudden death beyond infancy was rare in this large group of patients followed up over a long period. An early study cited an incidence of $19 \% .^{58}$ This included two infants less than three months of age, and without these it was $10 \cdot 7 \%$. Postmortem studies have indicated that sudden death is almost invariably associated with severe stenosis, and the ability to differentiate between moderate and severe stenosis is crucial. ${ }^{59}$ All reported cases of sudden death, other than two described by Reid, ${ }^{45}$ had symptoms, left ventricular strain pattern on electrocardiogram, or severe stenosis at cardiac catheterisation. A high incidence of sudden death $(6 \%)$ was reported by Keane et al..$^{49}$ Follow up, however, was infrequent with $26 \%$ of patients not having been seen for more than 10 years. With regular follow up and the routine use of cross sectional and Doppler echocardiography the risk of sudden death should fall below the reported incidences of $1 \%$ and $2 \% .{ }^{26}{ }^{60}$ There have not been any reports of sudden deaths in patients with mild aortic stenosis and therefore it seems unnecessary to restrict activity in patients with mild stenosis.

In our study, surgery was performed on patients with a peak systolic gradient of 60 $\mathrm{mm} \mathrm{Hg}$ to minimise the risk of sudden death. The validity of this approach was substantiated by the fact that there was only one sudden death in the group, giving an incidence of $0.3 \%$. Surgery or balloon dilatation can be performed before the development of severe stenosis and was a relatively safe palliation as no patient died from simple valvotomy other than those with critical stenosis. Of patients with valve stenosis $27 \%$ will require reoperation within 10 to 20 years, and about $70 \%$ of these reoperations will be a valve replacement. ${ }^{5051}$ The incidence of reoperation in patients with subaortic stenosis was lower in this study, but Stewart et al suggested that this increases with time. ${ }^{37}$

The severity of obstruction and age at presentation, as expected, significantly influenced survival. Within the early phase, hazard analysis showed that more severe obstruction of the left ventricular outflow tract and young age at presentation were the dominant factors modifying survival. Thereafter, hazard analysis showed the degree to which the type of obstruction affected continued survival (fig 1). Other studies have suggested that patients with multilevel obstruction seem to have a worse prognosis than those with a single level of obstruction, ${ }^{17} 1929$ but the relative prognosis of the various types of obstruction over a long period of follow up has not previously been documented. Factors that were found to be insignificant in term of survival were sex, aortic regurgitation at presentation, and the presence of other cardiac lesions.

In patients with a chromosomal abnormality, death may be attributable to other cardiac or non-cardiac factors. In patients with Williams', Shone's or Noonan's syndromes, or familial supravalve aortic stenosis, death was directly related to aortic stenosis. This explains the influence of a syndrome or other genetically inherited conditions as an independent risk factor in the constant phase of the hazard model for death.

\section{FREEDOM FROM CLINICAL EVENT}

Figure 3 (appendix 2) showed the noteable difference in the risk of an important clinical event depending on the severity of obstruction at presentation. All patients presenting with severe or critical stenosis underwent intervention within the first few months after presentation. There was also a considerable difference in the risk of a clinical event in patients presenting with mild or moderate obstruction. Patients presenting with moderate obstruction were at a higher risk of experi- 


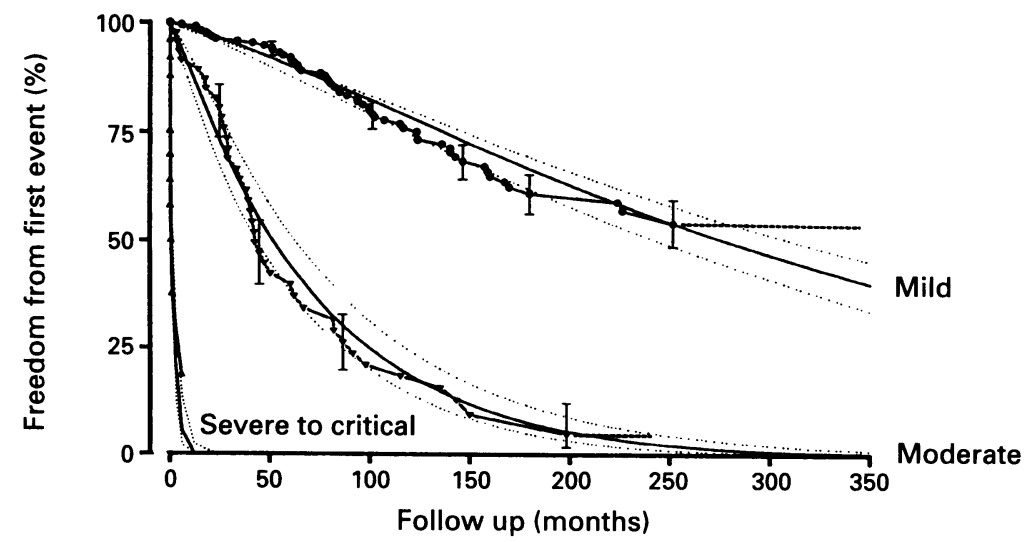

Figure 3 (appendix 2) Average, risk adjusted freedom from first clinical event (operation, balloon dilatation, or endocarditis, and $70 \% \mathrm{CIs}$ ) predicted from equations developed in the hazard analysis (appendix 1) stratified by severity of obstruction of left ventricular outflow tract at presentation (solid unbroken lines). Stratified actuarial plots (solid broken lines with symbols: occasional 70\% CIs plotted as error bars) are shown superimposed upon these. The dashed lines beyond the last event denote continued follow up of event free patients. By convention, the last event for the severe to critical group has not been plotted but occurred six months after presentation.

encing a clinical event for seven to eight years of follow up after which the risk seemed to fall a little. Patients presenting with mild stenosis had a lower and more or less constant incidence of intervention as the obstruction progressed with time.

It would be expected that the risk of experiencing an important clinical event such as operation, balloon dilatation, or endocarditis is likely to be related to the severity of the obstruction at presentation. Hazard analysis clearly indicated that this risk was also closely related to the type of obstruction (fig 2). There was no difference in the risk between patients with valve and supravalve obstruction. Unlike the multivariate analysis for death, the absence of any significant risk factor that showed a strong association with supravalve stenosis allowed the inference that when other risk factors were equal, a patient with supravalve stenosis had the same chance of experiencing a clinical event as a patient with valve stenosis. Patients with subvalve or multilevel obstruction fared worse. They were more likely to undergo intervention or develop endocarditis during childhood or adolescence, even when they presented with mild stenosis at a relatively older age (fig 2 ). Factors found to be insignificant in the risk of experiencing a first event were the sex, the presence of other cardiac lesions, or a syndrome.

\section{CURRENT STATE}

Progression of all types of obstruction of the left ventricular outflow tract is known to occur. ${ }^{49}$ Those with valve stenosis progressed at a slower rate, with just over $50 \%$ still having Doppler evidence of mild stenosis (without intervention) at the end of the study, compared with $25 \%-30 \%$ of those with subvalve or supravalve obstruction.

We wish to acknowledge the continued help of Dr Eugene $H$ Blackstone in the use of the parametric analysis of time related events in Liverpool.
Appendix I Hazard analysis relating to figs FREEDOM FROM DEATH (FIG 1)

(a) Shaping and scaling parameter estimates for survivorship and hazard function for death after presentation with obstruction of left ventricular outflow tract.

Two phases - early and constant-were resolved. The parameter estimates were as follows:

Early phase $\mathrm{mu}_{1}=0 \cdot 119801$, delta $=0$, rho $=$ $0 \cdot 161691, \mathrm{nu}=2 \cdot 207924, \mathrm{~m}=0$.

Constant phase: $\mathrm{mu}_{2}=0.000495$.

(b) Equations, co-efficients (SD) as $p$ values in the multivariate analysis of correlates of death after presentation.

Early phase: delta $=0$, rho $=0 \cdot 283543$, nu $=$ $2 \cdot 191723, \mathrm{~m}=0$, intercept $=0.023698$, severity of obstruction of left ventricular outflow tract at presentation (square transform $0.460(0.058)(\mathrm{p}<0.001)$, age at presentation (natural logarithmic transform) $-0.597(0.124)(p<0.001)$.

Constant phase: intercept $=0.000045$, severity of obstruction of left ventricular outflow tract at presentation $1.108(0.397)(p=0.005)$, presence of subvalve stenosis $1.106(0.654)(p=0.09)$, presence of multilevel obstruction $2.350(0.578)(\mathrm{p}<0.001)$ presence of syndrome $1.660(0.566)(p=0.003)$.

FREEDOM FROM FIRST EVENT (FIGS 2 AND 3)

(a) Shaping and scaling parameter estimates and hazard function for first event after presentation with obstruction of left ventricular outflow tract.

Two phases-early and constant-were resolved. The parameter estimates were as follows:-

Early phase: $\mathrm{mu}_{1}=0.031842$, delta $=0$, rho $=$ $0.023363, \mathrm{nu}=1.258976, \mathrm{~m}=0$.

Constant phase: $\mathrm{mu}_{2}=0.003393$.

(b) Equations, co-efficients (SD) as p values in the multivariate analysis of correlates for first event after presentation.

Late phase: gamma $=1$, tau $=2.015031$, alpha $=$ 0.337005 , eta $=0.468662$, intercept $=0.000005$, presence of severe stenosis at presentation $=3.003$ $(0.564)(p<0.001)$, severity of obstruction of left ventricular outflow tract at presentation (square root transform; $4.678(0.542)(\mathrm{p}<0.001)$, age at presentation (negative reciprocal transform; $-0.050(0.013)(p$ $<0.001)$, presence of aortic regurgitation at presentation $0.893(0.464)(p<0.05)$, presence of subvalve stenosis $0.907(0.242)(\mathrm{p}<0.001)$, presence of multilevel obstruction $1.378(0.287)(p<0.001)$.

Appendix 2 Risk of event free survival related to fig 3

When the two phase parametric model of the event free survival distribution was associated with risk factors, it became clear that the small early phase was entirely attributable to the 13 patients who presented with severe or critical stenosis and underwent surgical intervention less than six months after presentation. In an effort to accommodate the high risk of these patients, the intercept for the early phase fell to a valve not significantly different from zero. Thus identification of this high risk subgroup as the sole contributor to the short lived early phase of hazard completely explained this phase of the model.

Under these circumstances, the constant phase was found to rise slightly, prompting a significant respecification of the initial parametric model that involved modelling these early events by incorporating them into a general late phase model that described all events across the total experience. Concerned that the resultant risk factors were able to account for the poor prognosis of patients with severe to critical stenosis, we performed a validation exercise with patient specific risk adjusted parametric predictions that were stratified and superimposed on the actuarial data. The excellent fit of the risk adjusted parametric predictors to the actuarial data for all degrees of obstruction (fig 3) confirms the validity of our model in making predictions for groups with disparate underlying hazard rates. 
1 Hossack KF, Neutze JM, Lowe JB, Barratt-Boyes BG. Congenital valvar aortic stenosis. Natural history and assessment for operation. Br Heart $\mathcal{F}$ 1980;43:561-73.

2 de Vries AG, Hess J, Witsenburg M, Frohn-Mulder IME, Bogers JC, Bos E. Management of fixed subaortic stenosis: a retrospective study of 57 cases. $f \mathrm{Am} \mathrm{Coll}$ Cardiol 1992;19:1013-7.

3 Wren C, Oslizlok P, Bull C. Natural history of supravalvular aortic stenosis and pulmonary artery stenosis. $\mathcal{A} \mathrm{Am}$ Coll Cardiol 1990;15:1625-30.

4 Kitchiner DJ, Jackson M, Walsh K, Peart I, Arnold R. The incidence and prognosis of congenital aortic valve The incidence and prognosis of congenital aortic valve
stenosis in Liverpool (1960-1990). Br Heart f 1993;69: 71-9.

5 Armitage P, Berry G. Statistical methods in medical research. 2nd ed Oxfond: Blackwell, 1987:371-421.

6 Kaplan EL, Meier P. Nonparametric estimation from incomplete observations. Foumal of the American Statistical Association 1958;53:457-81.

7 Blackstone EH, Naftel DC, Turner (Junior) ME. The decomposition of time varying hazard into phases, each incorporating a separate stream of concomitant information. Foumal of the American Statistical Association 1986;81:615-24

8 Braunwald E, Goldblatt A, Aygen MM, Rockoff SD, Morrow AG. Congenital aortic stenosis. I. Clinical and hemodynamic findings in 100 patients. Circulation 1963; 27:426-50

9 Hohn AR, Van Praagh S, Moore AAD, Vlad P, Lambert EC. Aortic stenosis. Circulation 1965;31(suppl III): 4-12.

10 Campbell $M$. The natural history of congenital aortic stenosis. Br Heart f 1968;30:514-26.

11 Edwards JE. Pathology of left ventricular outflow tract obstruction. Circulation 1965;31:586-99.

12 Shackleton J, Edwards FR, Bickford BJ, Jones RS. Longterm follow-up of congenital aortic stenosis after term follow-up of congenital a

13 Mody MR, Mody GT. Serial haemodynamic observations in congenital valvular and subvalvular aortic stenosis. Am Heart f 1975;89:137-43.

14 Edwards FR, Jones RS. Congenital aortic stenosis. Thorax 1962;17:218-29.

15 Cooley DA, Beall AC, Hallman GL, Bricker DL. Obstructive lesions of the left ventricular outflow tract. Surgical treatment. Circulation 1965;31:612-21.

16 Bernhard WF, Keane JF, Fellows KE, Litwin SB, Gross RE. Progress and problems in the surgical management of congenital aortic stenosis. F Thorac Cardiovasc Surg 1973;66:404-19.

17 Kirklin JW, Barratt-Boyes BG. Congenital valvar aortic stenosis. In: Kirklin JW, Barratt-Boyes BG, eds. Cardiac surgery. New York: John Wiley and Sons, 1986: surgery. 12 .

18 Chiariello L, Agosti J, Vlad P, Subramanian S. Congenital aortic stenosis. Experience with 43 patients. 7 Thorac aortic stenosis. Experience with
Cardiovasc Surg 1976;72:182-93.

19 Fisher RD, Mason DT, Morrow AG. Results of operative treatment in congenital aortic stenosis. Pre- and postoptreatment in congenital aortic stenosis. Pre- and postoperative hemodynamic

20 Keane JF, Fellows KE, La Farge CG, Nadas AS Bernhard WF. The surgical management of discrete and diffuse supravalvar aortic stenosis. Circulation 1976;54: 112-7.

21 Keith JD, Rowe RD, Vlad P. Heart disease in infancy and childhood, 2nd ed. New York: McMillan, 1967:3

22 Hoffman JIE. The natural history of congenital isolated pulmonic and aortic stenosis. Ann Rev Med 1969;20: $15-28$

23 Kenna AP, Smithells RW, Fielding DW. Congenital heart disease in Liverpool: 1960-1969. $Q$ f Med 1975;44: $17-44$.

24 Dickinson DF, Arnold R, Wilkinson JL. Ventricular septal defect in children born in Liverpool 1960 to 1969 . Evaluation of natural course and surgical implications in an unselected population. Br Heart $\mathcal{f} 1981 ; 46: 47-54$

25 Wagner HR, Ellison RC, Keane JF, Humphries JO, Nadas AS. Clinical course in aortic stenosis. Circulation 1977;56(suppl 1):47-56.

26 Glew RH, Varghese PJ, Krovetz LJ, Dorst IP, Rowe RD. Sudden death in congenital aortic stenosis. Am Heart $\dot{f}$ 1969;78:615-25.

27 Nadas AS. Pulmonary stenosis, aortic stenosis, ventricular septal defect: clinical course and indirect assessment Summary and conclusions. Circulation 1977;56: (suppl I):70-1

28 Brown JW, Stevens LS, Holly S, Robison R, Rodefeld M, Grayson T, et al. Surgical spectrum of aortic stenosis in children: a thirty-year experience with 257 children. Ann Thorac Surg 1988;45:393-403.

29 Salomon NW, Stinson EB, Oyer P, Copeland JG, Shumway NE. Operative treatment of congenital aortic stenosis. Ann Thorac Surg 1978;26:452-60.

30 Cohen LS, Friedman WF, Braunwald E. Natural history of mild congenital aortic stenosis elucidated by serial haemodynamic studies. Am f Cardiol 1972;30:1-5.

31 Williams JCP, Barratt-Boyes BG, Lowe JB. Supravalvular aortic stenosis. Circulation 1961:24:1311-8.

32 Jones KL, Smith DW. The Williams elfin facies syn- drome. A new perspective. $\mathcal{F}$ Pediatr 1975;86:718-23.

33 Brand A, Keren A, Reifen RM, Gross-Kieselstein E, Ami N. Echocardiographic and Doppler findings in the Williams syndrome. Am f Cardiol 1989;63:633-5.

34 Logan WFWE, Wyn Jones E, Walker E, Coulshed N, Epstein EJ. Familial supravalvar aortic stenosis. $B$ Heart $\mathcal{F}$ 1965;27:547-59.

35 McCue CM, Spicuzza TJ, Robertson LW, Mauck HP Familial supravalvular aortic stenosis. $f$ Pediatr 1968 ; 73:889-95.

36 Cassidy SC, Van Hare GF, Silverman NH. The probability of detecting a subaortic ridge in children with ventricular septal defect or coarctation of the aorta. $\mathrm{Am} \mathcal{f}$ Cardiol 1990;66:505-8.

37 Stewart JR, Merrill WH, Hammon JW, Graham TP Bender HW. Reappraisal of localized resection for subvalvar aortic stenosis. Ann Thorac Surg 1990;50 197-203.

38 Lawson RM, Bonchek LI, Menashe V, Starr A. Late results of surgery for left ventricular outflow tract obstruction in children. $\mathcal{f}$ Thorac Cardiovasc Surg 1976; 71:334-41.

39 Sandor GGS, Olley PM, Trusler GA, Williams WG Rowe RD, Morch JE. Long-term follow-up of patients after valvotomy for congenital valvular aortic stenosis in children. A clinical and actuarial follow-up. $\mathcal{F}$ Thorac Cardiovasc Surg 1980;80:171-6.

40 Newfeld EA, Muster AJ, Paul MH, Idress FS, Riker WL Discrete subvalvular aortic stenosis in childhood. Study of 51 patients. Am $\mathcal{F}$ Cardiol 1976;38:53-61.

41 Giddins NS, Finley JP, Nanton MA, Roy DL. The natural course of supravalvar aortic stenosis and peripheral artery stenosis in Williams's syndrome. Br Heart $\mathcal{f}$ artery stenosis

42 Flaker G, Teske D, Kilman J, Hosier D, Wooley C. Supravalvular aortic stenosis. A 20-year clinical perspective and experience with patch aortoplasty. $A m \mathcal{f}$ Cardiol 1983;51:256-60.

43 Sreeram N, Kitchiner D, Smith A. Spectrum of valvar abnormalities in Noonan's syndrome: a pathologic study. Cardiology in the young 1994;4:62-6.

44 Magenis E, Hecht F. In: Bergsma D, ed. Birth defects com pendium. New York: Macmillan Press, 1979:212-3.

45 Reid JM, Coleman EN, Stevenson JG. Management of congenital aortic stenosis. Arch Dis Child 1970;45 201-5.

46 Katz NM, Buckley MJ, Liberthson RR. Discrete membranous subaortic stenosis. Report of 31 patients, review of the literature, and delineation of management. Circulation 1977;56:1034-8.

47 Vogt J, Dische R, Rupprath G, de Vivie ER, Kotthoff St, Kececioglu D. Fixed subaortic stenosis: an acquired secondary obstruction? A twenty-seven year experience with 168 patients. Thorac Cardiovasc Surg 1989;37: 199-206.

48 Friedman WF, Pappelbaum SJ. Indications for haemodynamic evaluation and surgery in congenital aortic stenonamic evaluation and surgery in congenital a
sis. Pediatr Clin North $\mathrm{Am} 1971 ; 18: 1207-21$.

49 Keane JF, Dirscoll DJ, Gersony WM, Hayes CJ, Kidd I O'Fallon WM, et al. Second natural history study of congenital heart defects. Results of treatment of patients with aortic valvar stenosis. Circulation 1993;87(suppl I) 11-27.

50 Wheller J, Hosier DM, Teske DW, Craenen JM, Kilman $\mathrm{JW}$. Results of operation for aortic stenosis for aortic valve stenosis in infants, children, and adolescents. $\mathscr{f}$ Thorac Cardiovasc Surg 1988;96:474-7.

51 DeBoer DA, Robbins RC, Maron BJ, McIntosh CL Clark RE. Late results of aortic valvotomy for congenital valvar aortic stenosis. Ann Thorac Surg 1990;50: 69-73.

52 Sung C-S, Price EC, Cooley DA. Discrete subaortic stenosis in adults. Am $\mathcal{f}$ Cardiol 1978;42:283-90.

53 Sullivan ID, Wren C, Bain H, Hunter S, Rees PG, Taylor JFN, et al. Balloon dilatation of the aortic valve for congenital aortic stenosis in childhood. Br Heart $\mathcal{F} 1989$; 61:186-91.

54 Rocchini AP, Beekman RH, Ben Shachar G, Benson L Schwartz D, Kan JS. Balloon aortic valvuloplasty: results of the valvuloplasty and angioplasty of congenital
resula results of the valvuloplasty and angioplasty of conge

55 Suarez de Lezo J, Pan M, Medina A, Romero M, Melian $\mathrm{F}$, Segura J, et al. Immediate and follow-up results of $\mathrm{F}$, Segura J, et al. Immediate and follow-up results of transluminal balloon dilatation for discrete

56 Stewart JR, Paton BC, Blount SG, Swan H. Congenital aortic stenosis. Ten to 22 years after valvulotomy. Arch Surg 1978;113:1248-52.

57 Fontana RS, Edwards JE. Congenital cardiac disease: review of 357 cases studied pathologically. Philadelphia: WB Saunders, 1962:291.

58 Marquis RM, Logan A. Congenital aortic stenosis and its surgical treatment. Br Heart $\mathcal{F} 1955 ; 17: 373-90$

59 Reynolds JL, Nadas AS, Rudolf AM, Gross RE. Critica congenital aortic stenosis with minimal electrocardiographic changes. A report on two siblings. N Engl $\mathcal{F} M e d$ 1960;262:276-82.

60 Peckham GB, Keith JD, Evans JR. Congenital aortic stenosis: some observations on the natural history and clinical assessment. Can Med Assoc F 1964;91:639-43. 
unknown. Although auto-immune related thyrotoxicosis has been reported after amiodarone treatment, ${ }^{6}$ neither of our patients had a goiter or thyroid antibodies before amiodarone treatment and antibodies did not develop during follow up.

These data suggest that amiodarone induced thyrotoxicosis has a peculiar pathogenesis. When intrathyroidal amiodarone concentrations exceed a threshold, cell damage leads to thyrotoxicosis when the contents of the thyroid leak into the bloodstream. The intra-thyroidal concentration of amiodarone too would decrease, allowing repair and the restoration of euthyroidism. If this hypothesis is true, continuation of amiodarone treatment might eventually lead to a recurrence of thyrotoxicosis when the intrathyroidal amoidarone concentration again exceeds the threshold.
In our patients the follow up period was probably too short for a second period of thyrotoxicosis to develop.

1 Trip MD, Wiersinga WM, Plomp ThA. Incidence, predictability and pathogenesis of amiodarone induced thyrotoxicosis and hypothyroidism. Am f Med 1991;91: 507-11.

2 Smyrk TC, Goellner JR, Brennan MD, Carney JA Pathology of the thyroid in amiodarone-associated thyrotoxicosis. Am ₹ Surg Pathol 1987;11:197-204.

3 Martino E, Aghini-Lombardi F, Mariotti S. Treatment of amiodarone associated thyrotoxicosis by the simultaneous administration of potassium perchlorate and methious administration of potassium perchlorate

4 Reichert LJM, de Rooy HAM. Treatment of amiodarone induced hyperthyroidism with potassium perchlorate and methimazole during amiodarone treatment. $\mathrm{Br} M e d f$ 1989;298:1547-8

5 Brennan MD, van Heerden JA, Carney JA. Amiodaroneassociated thyrotoxicosis (AAT): Experience with surgical management. Surgery 1987;102:1062-7.

6 Martino E, Macchia E, Aghhini-Lombardi F, et al. Is humoral thyroid autoimmunity relevant in Amiodaroneinduced thyrotoxicosis (AIIT)? Clin Endocrinol 1986;24: 627-33.

\section{CORRECTION}

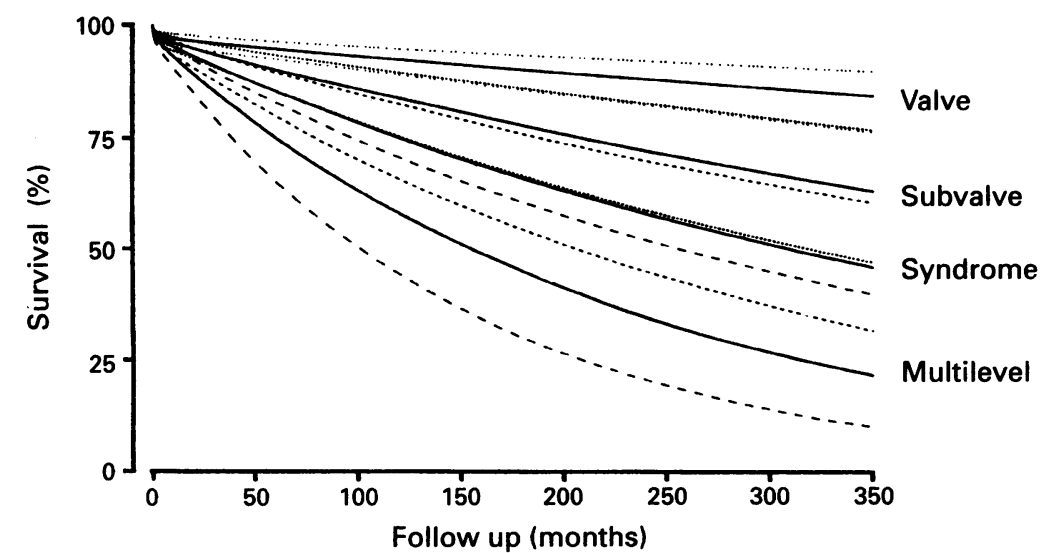

Figure 1 Predicted risk of death (and 70\% CIs) for a patient presenting at 13.9 months of age with moderate obstruction of the left ventricular outflow tract plotted against level of obstruction from a solution to equations developed by means of hazard analysis (appendix 1).
Incidence and prognosis of obstruction of the left ventricular outflow tract in Liverpool (1960-91): a study of 313 patients

D Kitchener, $M$ Fackson, N Malaiya, KWalsh, I Peart, $R$ Arnold

We regret that owing to a printer's error figure 1 and figure 2 in this article in the June issue (Br Heart $\mathcal{F} 1994 ; 71: 588-95)$ appeared in the wrong order and with the wrong legends. The corrected versions are reprinted on the left.

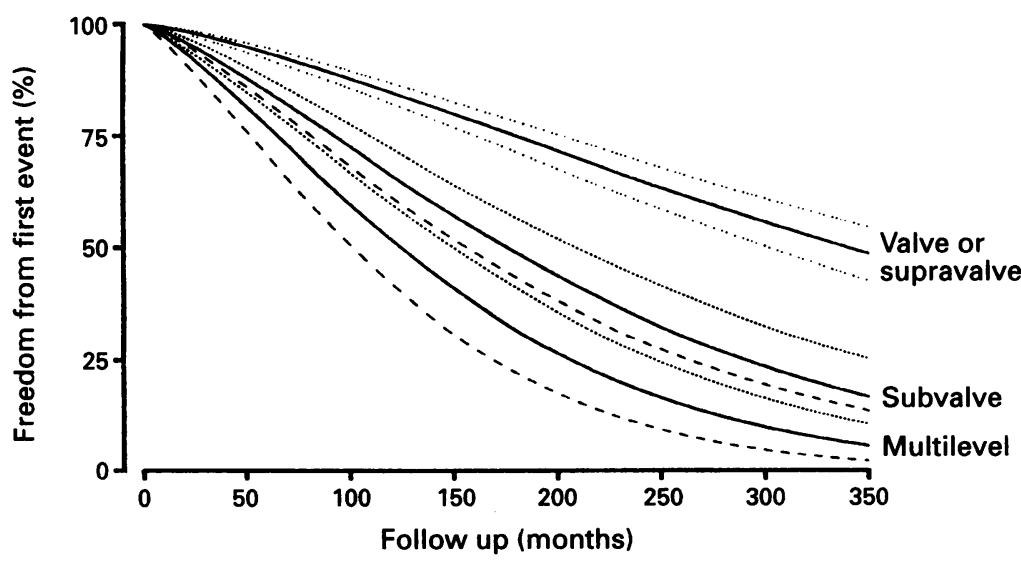

Figure 2 Predicted freedom from first clinical event (operation, balloon dilatation or endocarditis, and $70 \%$ CIs) for a patient presenting at 13.9 months of age with mild obstruction of left ventricular outflow tract without aortic regurgitation plotted against level of obstruction from equations developed by means of hazard analysis (appendix 1). 